\title{
Dinâmica espaço-temporal da comunidade de peixes em baías marginais do Pantanal Norte
}

Este estudo teve como objetivo investigar o impacto do ciclo hidrológico na estrutura da comunidade ictiológica em seis baías marginais do rio Paraguai durante os períodos de cheia, vazante, estiagem e enchente no Pantanal Norte. As coletas foram realizadas com a utilização de redes de arrasto, espera e tela entre 2014 e 2015. Para a análise dos dados foram aplicados os índices de diversidade alfa e beta. Ao todo foram coletados 7.318 espécimes, em que a maior riqueza, abundância e diversidade, foram observadas no período de estiagem. Contrastando a maior disponibilidade de abrigo e alimento em locais heterogêneos, normalmente representado por ambientes maiores, ou nas cheias pantaneiras, as maiores diversidades beta foram encontradas em baías de menores comprimentos, menores larguras e consequentemente menores áreas. Ainda que o período de cheia no pantanal seja considerado aquele com maior disponibilidade de recursos, destaca-se que as baías marginais, desde as pequenas, podem abrigar uma diversidade de espécies alta também em períodos de águas baixas. A alta homogeneidade das espécies encontradas indica que estas não dependem dos locais e dos períodos amostrais para ocorrerem, o que pode ser reflexo da conectividade com o canal principal do rio Paraguai durante o ano todo.

\section{Spatial and temporal dynamics from the fish community in the marginal lakes at the Northern Pantanal}

\begin{abstract}
This study investigates the impact of the hydrological cycle on the ichthyological community structure in six marginal lakes on the Paraguay river during the high, ebb, low and raising waters in the Northern Pantanal. The samples were performed with nets of different sizes between 2014 to 2015 . To analyse the data, we used the alfa and beta diversity indexes. In total, 7,318 individuals were sampled, and the highest richness, abundance and consequently diversity was observed during the low waters. Contrasting the high availability of shelter and food in heterogenous places, normally represented by bigger environments, or during the high waters in the Pantanal, the highest beta diversity was found in the marginal lakes of lower sizes (length, width and area). Although the high waters in the Pantanal is considered that with most availability of resources, we highlight that the marginal lakes, even the small ones, may host a high diversity of species in periods of low waters as well. The high homogeneity of species shows that they are not dependent on the space and seasons to be in the environment, which may be an effect of the connectivity to the main channel of the Paraguay river throughout the entire year.
\end{abstract}

Keywords: Hydrological Seasons; Ichthyofauna; Hydrological Morphometry.

Topic: Desenvolvimento, Sustentabilidade e Meio Ambiente

Reviewed anonymously in the process of blind peer.
Received: 02/12/2018

Approved: 26/01/2019
Francimayre Aparecida Pereira de Jesus (ic) Universidade do Estado de Mato Grosso, Brasil http://lattes.cnpq.br/6642769846888600 http://orcid.org/0000-0002-1617-9725 francy21pereirajv@gmail.com

\section{Larissa Nayara Lima Silva (iD}

Universidade do Estado de Mato Grosso, Brasil http://lattes.cnpq.br/1900114813439396 http://orcid.org/0000-0003-3140-6188 larissa lima1507@hotmail.com

Priscila Campos Santos (iD

Universidade do Estado de Mato Grosso, Brasil http://lattes.cnpq.br/3312544039354251 http://orcid.org/0000-0002-6400-4129 pricampossantos@gmail.com

\author{
Ernandes Sobreira Oliveira Junior (iD) \\ Universidade do Estado de Mato Grosso, Brasil \\ http://lattes.cnpq.br/7461346615427709 \\ http://orcid.org/0000-0002-6953-6917 \\ ernandes.sobreira@gmail.com \\ Derick Victor de Souza Campos (iD) \\ Universidade do Estado de Mato Grosso, Brasil \\ http://lattes.cnpq.br/2785712474480148 \\ http://orcid.org/0000-0002-7995-9585 \\ axlderick@gmail.com \\ Wilkinson Lopes Lázaro (iD \\ Universidade do Estado de Mato Grosso, Brasil \\ http://lattes.cnpq.br/0263718697915954 \\ http://orcid.org/0000-0002-6499-6631 \\ wilkisonlopes@gmail.com
}

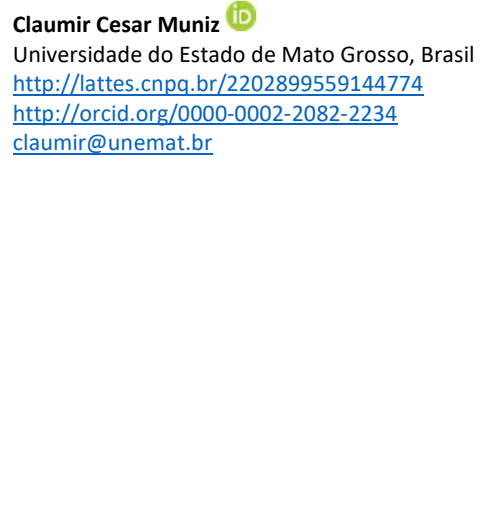

umir Cesar Muniz (10) http://orcid.org/0000-0002-2082-2234 claumir@unemat.br

\section{Referencing this:}

JESUS, F. A. P.; SILVA, L. N. L.; OLIVEIRA JUNIOR, E. S.; CAMPOS, D. V. S.; LÁZARO, W. L.; MUNIZS, C. C.. Dinâmica espaço-temporal da comunidade de peixes em baías marginais do Pantanal Norte. Revista Ibero Americana de Ciências Ambientais, v.10, n.1, p.232-240, 2019. DOI: http://doi.org/10.6008/CBPC2179-6858.2019.001.0019

DOI: 10.6008/CBPC2179-6858.2019.001.0019 


\section{INTRODUÇÃO}

O pantanal está localizado na parte central da América do sul, ocupando uma área de aproximadamente $140.000 \mathrm{~km}^{2}$, na bacia do alto rio Paraguai, entre os estados de Mato Grosso e Mato Grosso do Sul (SILVA et al., 1993). Este ambiente caracteriza-se por ser uma grande planície alagável localizada em uma grande depressão, com áreas de drenagem lenta que se inundam periodicamente (JUNK et al., 1980; JUNK et al., 1989).

O Pantanal apresenta uma das mais exuberantes e diversificadas reservas naturais do planeta, com alta prioridade para conservação (BRASIL, 1988). Este bioma tem o rio Paraguai como principal formador, e recebe águas de inúmeros afluentes, como os rios Cuiabá, São Lourenço, Jauru e Sepotuba no Mato Grosso, e os rios Taquari, Miranda, Aquidauana e Apa no Mato Grosso do Sul. O rio Paraguai tem suas nascentes em território brasileiro no planalto dos Parecis no estado do Mato Grosso fluindo de norte a sul, percorrendo uma extensão de $2.621 \mathrm{~km}$, dos quais $1.693 \mathrm{~km}$ em território brasileiro, até sua confluência com o rio Paraná na cidade de Corrientes, Argentina (INNOCENCIO, 1977).

No Pantanal o pulso de inundação é condicionado principalmente pelo ciclo de chuvas durante os meses de novembro a março, contrastando os meses de estiagem de agosto a outubro (RESENDE, 1998; MUNIZ, 2010). A dinâmica das águas é a principal força reguladora das comunidades biológicas especialmente nas assembleias de peixes, pois controla a estrutura e o seu funcionamento tendo um papel importante na ciclagem de nutrientes e na disponibilidade de abrigo, alimento e habitat já que proporciona diferentes ambientes nos períodos sazonais (MCCONNELL, 1987; RESENDE et al., 1996; RODRIGUEZ, 1997; ESTEVES, 1998). Neste ambiente, 269 espécies de peixes são reconhecidas sendo distribuídas em 11 ordens e 31 famílias (BRITSKI et al., 2007), e devido a dinâmica das águas estes organismos apresentam diferenças em sua biologia, morfologia, e na ocupação dos habitats (BRITSKI et al., 2007; HELFMAN et al., 2009).

Desta forma, a estrutura de comunidades deve se diferir de acordo com a escala temporal, principalmente devido a movimentação das águas, mas também em escala espacial, sendo o Pantanal bastante diverso no que tange a morfologia dos cursos d'água. De acordo com a escala temporal ou histórica, as mudanças no ambiente fazem com que as espécies se ajustem, adaptando-se ao mesmo através de mudanças morfológicas, fisiológicas e comportamentais (RODRIGUEZ et al., 1997; RODRIGUEZ, 2000). Em escala espacial fatores como heterogeneidade de habitats, competição e predação agem localmente e podem afetar a abundância e distribuição das espécies (CORNELL et al., 1992; BARROS, 2007), bem como as barreiras geográficas (RICKLEFS, 1987) como exemplo a presença de baías marginais, os quais reduzem o fluxo (influxo e efluxo) de água com o rio Paraguai, e até mesmo se isolam durante a estiagem pantaneira (MUNIZ, 2010).

Esta redução no fluxo das águas em relação as baías marginais também influenciam na composição de espécies da comunidade ictiológica (PAINS et al., 2010) pois reduz também a disponibilidade hídrica e consequentemente a migração lateral desses organismos entre o rio e as baías marginais (RESENDE et al., 2006). Além disso, a disponibilidade de recursos alimentares, como por exemplo a diversidade de 
macroinvertebrados também é alterada nestas baías marginais conforme o período sazonal (SOUZA et al., 2018).

Desta forma, a integração entre a heterogeneidade de habitat (baías marginais) e a sazonalidade são essenciais para a compreensão da estrutura da comunidade ictiológica do rio Paraguai, principalmente na porção norte, onde várias baías se desconectam do canal principal do rio durante o período de estiagem, e se juntam com o rio e com outras baías durante o período de cheia (MUNIZ, 2010). Sendo as baías marginais ambientes importantes para a ecologia das espécies, e as considerando bastante heterogêneas, principalmente quando retratada a dinâmica das águas, este trabalho investiga a estrutura das comunidades e a diversidade de espécies pantaneiras em seis baías marginais ao rio Paraguai durante um ciclo hidrológico completo.

\section{MATERIAIS E MÉTODOS}

As coletas foram realizadas no rio Paraguai, município de Cáceres (MT), até os limites da Estação Ecológica de Taiamã, a partir de fevereiro de 2014 a janeiro de 2015, contemplando os quatros períodos sazonais cheia, vazante, estiagem e enchente. Os pontos de coleta foram previamente definidos a partir de observações em imagens de satélite no período da seca, o que possibilitou a escolha de baías permanentes com distância média de 18,2 km uma da outra. As seis baías estão situadas ao longo do rio Paraguai,

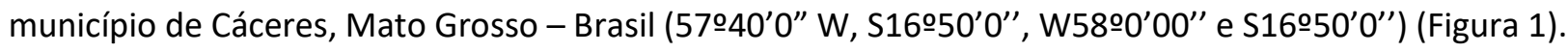

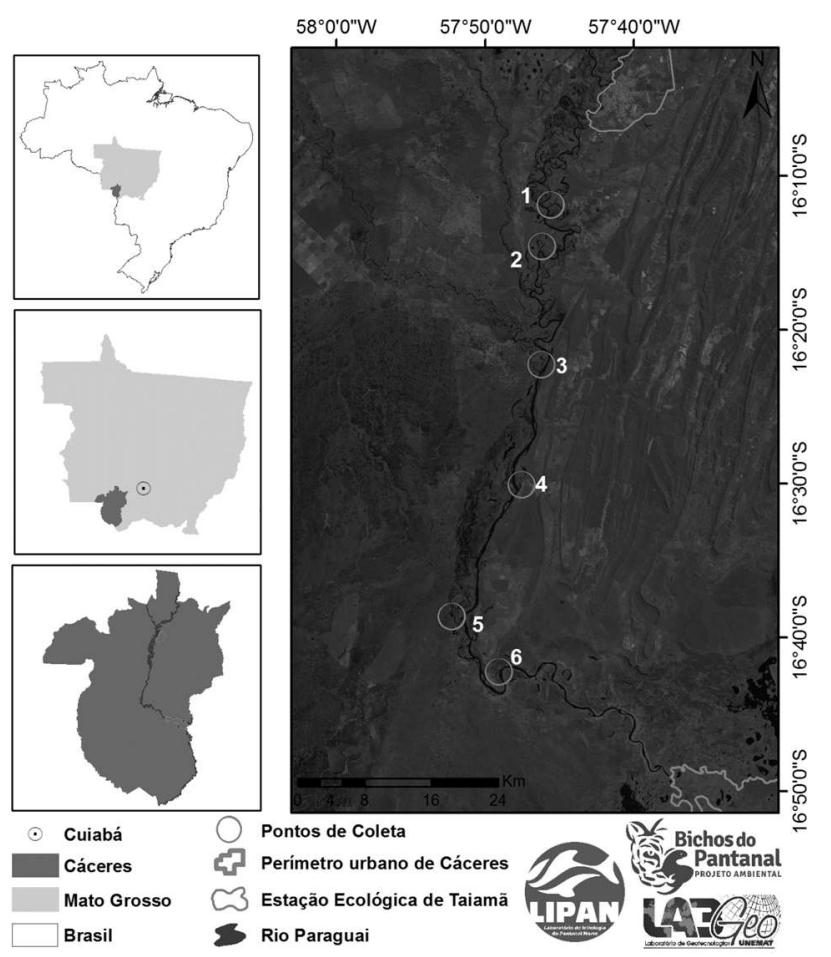

Figura 1: Área de estudo: localização dos seis pontos de coleta entre a cidade de Cáceres/MT e a Estação Ecológica de Taiamã.

Os materiais utilizados para as coletas foram: tela de nylon em armação metálica de 2,0m x 1,0m, rede de arrasto, rede de emalhar de 2, 3, 4, 5 e $6 \mathrm{~mm}$ entre nós. Para cada ponto passou-se a tela três vezes 
consecutivas sob os bancos de macrófitas aquáticas, e as redes de espera foram armadas com distância de aproximadamente 10 metros entre uma rede e outra, com tempo de espera de 2 horas.

Após a realização das coletas, os espécimes foram armazenados em sacos plásticos identificados, condicionados e fixados em solução de formalina $10 \%$ e encaminhados ao Laboratório de Ictiologia do Pantanal Norte (LIPAN), a identificação foi de acordo com o manual de identificação para peixes do pantanal (BRITSKI et al., 2007). Para avaliar a diversidade alfa ( $\alpha$ ) foi aplicado o índice de Shannon - Wiener (MAGURRAN, 1998), sendo descrita como:

$$
\mathrm{H}=\Sigma \mathrm{pi} . \ln \mathrm{PI}
$$

Onde: $\mathrm{Pi}=$ frequência de cada uma das espécies; In= logaritmo natural

A diversidade beta (ß) foi avaliada pelo índice de Whittaker, que mede a mudança ou taxa de substituição na composição de espécies de um local para outro (WHITTAKER, 1960). Este índice varia de 0 , quando duas amostras não apresentam nenhuma diferença na composição de espécies e 2, quando esta diferença é máxima, sendo calculado pela fórmula:

$$
\begin{array}{r}
B=(c / a)-1 \\
c=\text { total de espécies nas parcelas amostradas; } \\
\text { Onde: } \\
\text { = média do número de espécies das parcelas amostradas. }
\end{array}
$$

\section{RESULTADOS}

Nossos resultados demonstraram que nas seis baías marginais durante um ciclo hidrológico foram coletados 38\% das espécies reconhecidas para o Pantanal distribuídas em 7.318 espécimes pertencentes a 8 ordens (Characiformes, Siluriformes, Perciformes, Gymnotiformes, Beloniformes, Synbranchiformes, Cyprinodontiformes, Lepidosireniformes) e 30 famílias, sendo Characidae (30\%), Cichlidae (11\%) e Pimelodidae (6\%) as mais representativas (Figura 2). Dentre as oito ordens observadas destacam-se os Characiformes com 58 espécies, sendo predominante a riqueza e abundância seguido de Siluriformes e Perciformes com 20 e 11 espécies respectivamente.

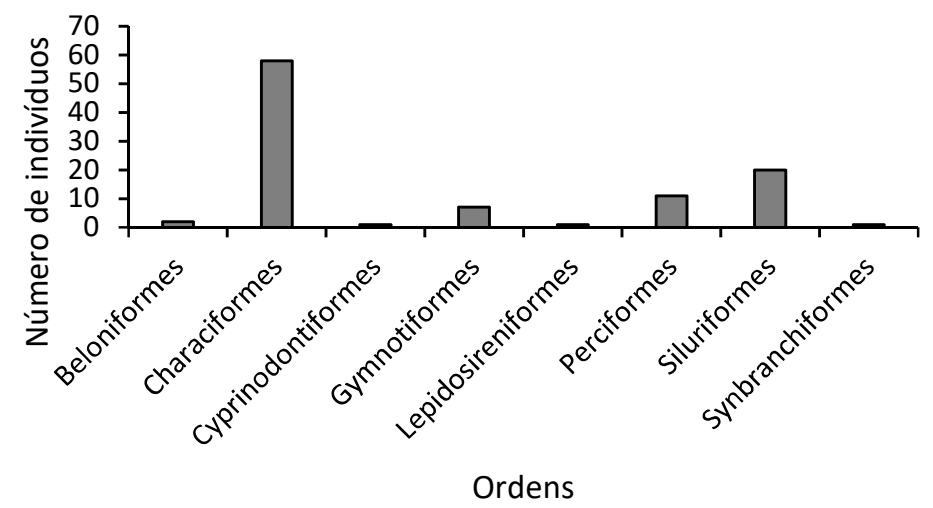

Figura 2: Distribuição das ordens dos peixes registradas nos seis pontos de coletas durante um ciclo hidrológico pantaneiro. 
A maior riqueza foi observada na baía 1, região mais próxima a cidade de Cáceres, com 59 espécies no período de estiagem, e a menor riqueza na baía 3 com 4 espécies no período de cheia. A maior abundância de espécies também ocorreu na estiagem, com destaque para a baía 1 e baía 6 com respectivamente 1297 e 1152 espécimes. A enchente e cheia demonstraram menor quantidade de indivíduos amostrados com 392 e 590 espécimes (Tabela 1).

Tabela 1: Estrutura da comunidade ictiológica em relação a dinâmica temporal (sazonalidade) e espacial (seis baías marginais) no rio Paraguai. Resultados em negrito demonstram os maiores valores encontrados.

\begin{tabular}{|c|c|c|c|c|c|c|c|c|c|c|c|c|c|c|c|c|}
\hline & \multicolumn{4}{|c|}{ Riqueza } & \multicolumn{4}{|c|}{ Abundância } & \multicolumn{4}{|c|}{ Diversidade $(\alpha)$} & \multicolumn{4}{|c|}{ Equitabilidade } \\
\hline & Che & Vaz & Est & Ench & Che & Vaz & Est & Ench & Che & Vaz & Est & Ench & Che & Vaz & Est & Ench \\
\hline Baía 1 & 21 & 38 & 59 & 12 & 175 & 250 & 1297 & 39 & 2.56 & 3.91 & 4.47 & 1.94 & 0.58 & 0.74 & 0.76 & 0.54 \\
\hline Baía 2 & 9 & 43 & 43 & 11 & 130 & 533 & 827 & 44 & 2.21 & 4.21 & 4.21 & 2.13 & 0.70 & 0.77 & 0.77 & 0.66 \\
\hline Baía 3 & 4 & 28 & 33 & 77 & 74 & 167 & 350 & 34 & 0.38 & 3.94 & 3.92 & 1.55 & 0.19 & 0.82 & 0.77 & 0.55 \\
\hline Baía 4 & 13 & 27 & 43 & 12 & 118 & 189 & 623 & 42 & 2.5 & 3.49 & 3.99 & 3.15 & 0.67 & 0.73 & 0.73 & 0.87 \\
\hline Baía 5 & 6 & 33 & 38 & 2 & 46 & 531 & 271 & 7 & 1.91 & 3.38 & 3.79 & 0.59 & 0.77 & 0.67 & 0.72 & 0.59 \\
\hline Baía 6 & 6 & 19 & 34 & 27 & 47 & 92 & 1152 & 280 & 1.5 & 3.25 & 3.95 & 3.35 & 0.39 & 0.76 & 0.58 & 0.70 \\
\hline
\end{tabular}

As estimativas de diversidade alfa considerando todas as baías amostradas e todos os períodos foram menores no período de cheia e maiores no período estiagem, variando de 0,38 a 4,47 respectivamente (Figura 3). A equitabilidade variou de 0,19 a 0,87 onde a baía 4 durante o período de estiagem obteve maior homogeneidade comparando as baías entre os períodos sazonais (Tabela 1).
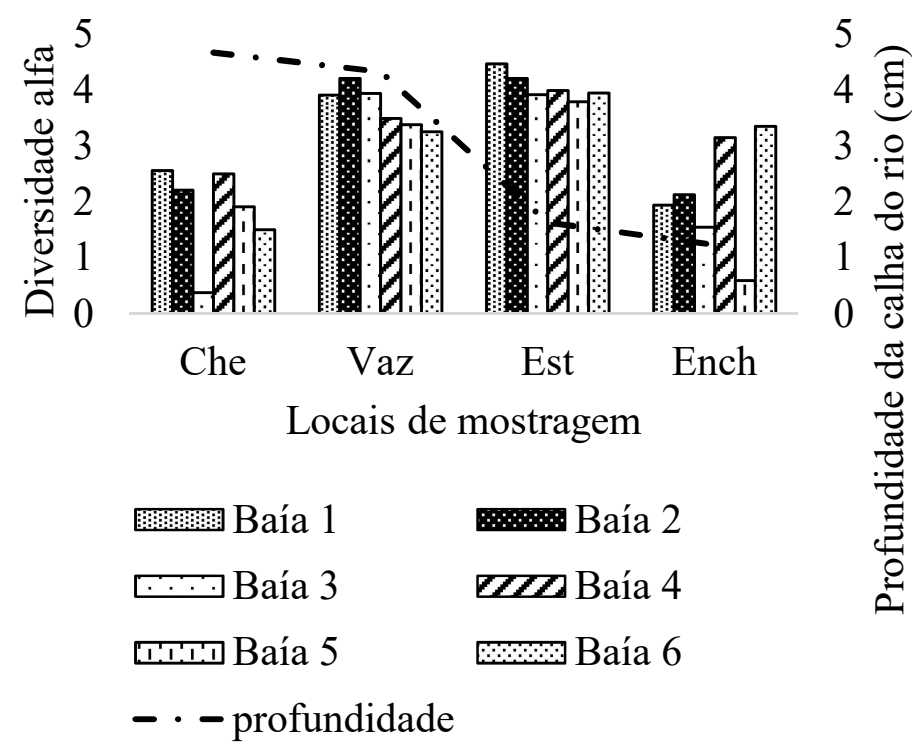

Ench

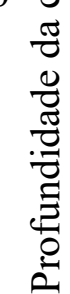

Figura 3: Diversidade alfa entre os locais de amostragem durante um período hidrológico completo comparando com o nível do rio Paraguai.

Os resultados da diversidade beta (comparando-se as baías independentemente do período sazonal) demonstraram diferenças significativas na composição das espécies em relação aos ambientes amostrados, variando de 1,35 a 1,68 $(P<0,05)$, em que a baía 1 registrou o menor valor e a baía 4 se destacou com o maior. Ao analisarmos a diversidade beta em relação as características das baías amostradas identificamos uma relação negativa significativa entre a diversidade beta e o comprimento máximo da baía $\left(R^{2}=0,66 ; P<\right.$ $0,05)$, assim como para a largura máxima $\left(R^{2}=0,78 ; P<0,05\right)$, e para a área total $\left(R^{2}=0,77 ; P<0,05\right)$, onde 
as maiores diversidades beta foram encontradas em baías de menores comprimentos, menores larguras e menores áreas (Figura 4 A, B e C respectivamente).
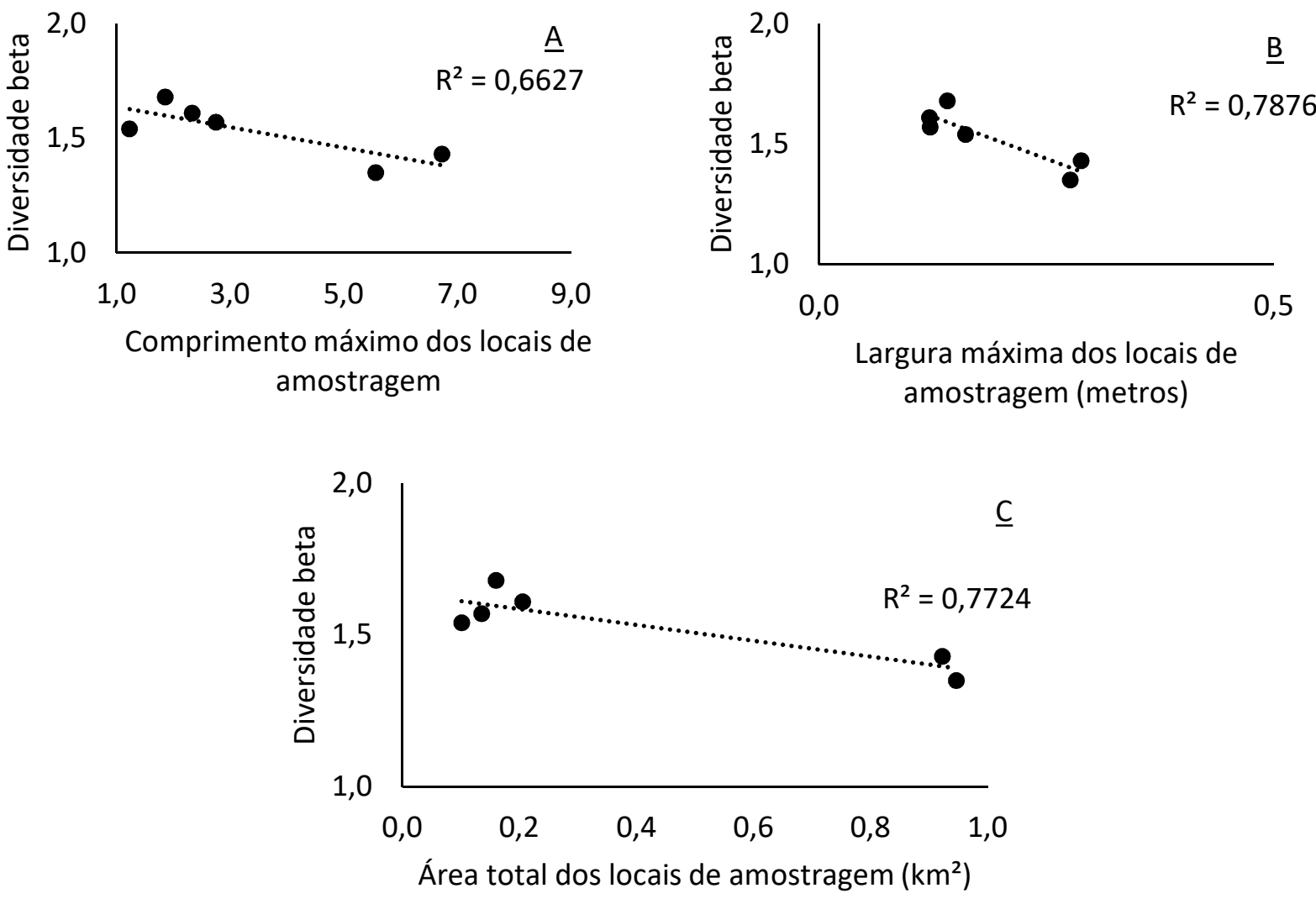

Figura 4: Diversidade beta nos seis pontos de amostragem durante um período hidrológico completo em relação ao comprimento máximo (A), largura máxima (B) e área total (C).

A análise de Cluster comparando as distâncias entre as comunidades das 6 baías amostradas demonstrou que a composição das comunidades mais similares foram as da baía 2 e 6 com diversidade beta 1,54 e 1,57 respectivamente, e a baía 4 foi a mais distinta se destacando com a maior diversidade (Figura 5).

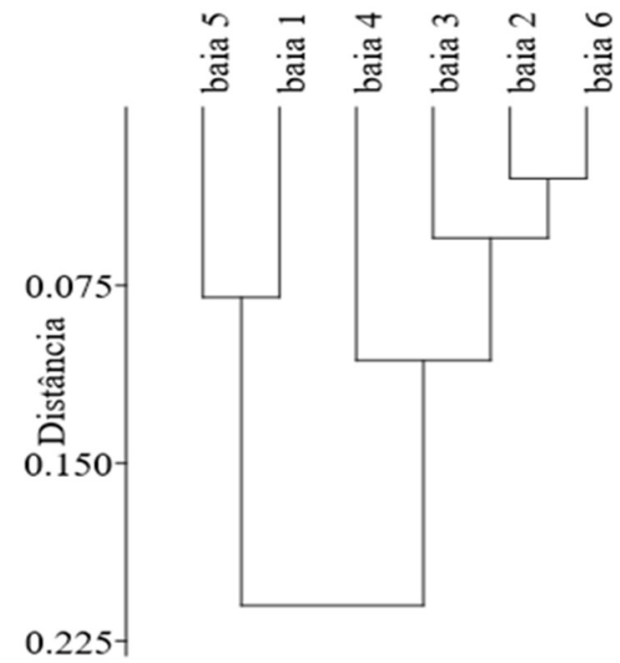

Figura 5: Distância euclidiana entre as comunidades nas seis baías amostradas durante um ciclo hidrológico completo. 


\section{DISCUSSÃO}

A riqueza nos seis pontos amostrados (101 espécies) representa 38\% do total descrito por Britski et al. (2007) para todo o sistema do Pantanal, demonstrando a importância das baías marginais para a manutenção da biodiversidade ictiológica pantaneira. Estes ambientes são altamente produtivos (BONETTO et al., 1969), o que reflete na alta riqueza encontrada para o local.

Dentre as ordens observadas os Characiformes foram os mais abundantes, em que a ictiofauna da América do Sul é caracterizada pela dominância da mesma sobre Siluriformes, isso ocorre devido à sua maior complexidade entre os peixes neotropicais em que a variedade de formas corporais permitem a ocupação de diferentes habitats e o desenvolvimento de estratégias alimentares diversificadas (BRITSKI et al., 1999; LOWE-MCCONNELL, 1999; NELSON, 2006; GRAÇA et al., 2007).

A riqueza e a abundância de espécies foram maiores na estiagem, assim como em outros estudos realizadas no Pantanal Norte, conforme Moura, 2010, Muniz, 2010 e Oliveira, 2012. Essa relação entre a maior riqueza e abundância no período de estiagem pode estar relacionada com a intrínseca ligação do pulso de inundação com a estrutura das comunidades biológicas, principalmente nas assembleias de peixes ocorrendo uma retração no espaço, reduzindo a área de forrageio fazendo com que as espécies se mantinham mais concentradas naquele ambiente, otimizando a captura (MCCONNELL, 1987; RESENDE et al., 1996; RODRIGUEZ, 1997; ESTEVES, 1998).

Já o período de enchente e cheia foi observado menor amostragem devido ao extravasamento da água na planície que invade os campos aumentando a oferta de alimentos ocasionando a dispersão dos peixes reduzindo a quantidade por relativo esforço de captura, podendo também estar relacionado com o aumento da profundidade (Figura 3) levando a diminuição da vulnerabilidade dos peixes (RESENDE et al., 1996; SOUZA, 2011).

A diversidade alfa apresentou oscilação temporal em todos as baías estudados, expressando diferentes padrões de diversidade entre as seis áreas, o que demonstra uma relação intrínseca com o período sazonal. A dinâmica hidrológica da planície pantaneira associada a morfologia de cada baía amostrada corrobora com estudos que demonstram que diferentes biótopos determinam a qualidade da biodiversidade encontrada (LEMES et al., 2012).

Nas baías amostradas observa-se a nítida influência temporal sobre a composição estrutural nas comunidades de peixes, assim como outros estudos realizados em ambientes alagáveis pantaneiros (BAGINSKI, 2007; MUNIZ, 2010), porém contrasta com estudos relativos a espacialidade, onde remetem que corpos d'água maiores apresenta maior diversidade. Os resultados observados por Súarez (2008) e Lemke et al. (2014) estudando a variação espaço/temporal na diversidade e composição de espécies de peixes em riachos da do Rio Ivinhema, Alto Rio Paraná, ao analisarem a diversidade beta e composição de espécies de peixes, constatou correlação positiva com a largura dos ambientes amostrados. Desta forma, os riachos com maior profundidade e largura tendem a ter maior riqueza de espécies e maior diversidade beta. $\mathrm{O}$ fato de nossos resultados apresentarem uma relação inversa pode, assim como para o período sazonal, se remeter 
a retração espacial hídrica e a maior facilidade de captura em ambientes menores, o que pode ter determinado maiores diversidade em baías com menores comprimentos, larguras e áreas totais em nosso estudo.

Mesmo a diversidade se apresentado de forma diferenciada temporalmente e espacialmente, o índice de equitabilidade ou uniformidade demonstrou que em todas baías estudadas a distribuição foi uniforme (valores maiores do que 0,50) significando que não há dominância entre as espécies apesar da complexidade da comunidade estando bem distribuídas, assim como encontrado por Botini et al. (2015). É importante salientar que as espécies encontradas foram, em grande maioria, de pequeno porte $(1-20 \mathrm{~cm}$; dados não apresentados), o que pode identificar as baías marginais como refúgio do canal principal em qualquer período sazonal.

\section{CONCLUSÕES}

Os resultados demonstra que a espacialidade e a temporalidade das águas pantaneiras pode determinar a dinâmica das comunidades ictiológicas, sendo que áreas menores podem apresentar maiores diversidades devido a condensação das espécies, influenciando os resultados dos índices de diversidade apresentados. Argumenta-se que mesmo a abundância ter sido maior durante o período de estiagem, refletindo no consequente mais alto índice de diversidade, nota-se que há uma uniformidade na manutenção das espécies independente dos locais e dos períodos amostrais, o que pode ser reflexo da conectividade com o canal principal do rio Paraguai. Assim, nosso estudo demonstra que mesmo o período de águas altas no pantanal sendo considerado aquele com maior disponibilidade de recursos alimentares e habitat, as baías marginais, desde as pequenas podem abrigar uma diversidade alta de espécies também em períodos de águas baixas.

AGRADECIMENTOS: Agradecemos ao Projeto Bichos do Pantanal, através do Programa Petrobras Socioambiental pelo apoio e financiamento.

\section{REFERÊNCIAS}

BAGINSKI, L. J.; FLORENTINO, A. C.; FERNANDES, I. M.; PENHA, J. M. P.; MATEUS, L. A. F.. The spatial and temporal dimension of fish diversity of the vegetated littoral zone of marginal lagoons of the Cuiabá river floodplain, Pantanal, Brazil. Biota Neotrop, v.7, n.3, 2007.

\section{BARROS, R. S. M.. Medidas de diversidade} biológica. Dissertação (Programa de Pós-Graduação em Ecologia Aplicada ao Manejo e Conservação de Recursos Naturais) - Universidade Federal de Juiz de Fora, 2007.

BONETTO, A.; DIONI, W.; PIGNALBERI, C.. Limnological investigations on biotic communities in the Middle Paraná River Valley: With 9 figures and 2 tables in the text. Internationale Vereinigung für theoretische und angewandte Limnologie, Verhandlungen, v.17, n.2, p.10351050, 1969
BOTINI, A. F.; BARROS, C. A.; SOUZA, T. H.; BOTINI, N.; MOURA, N. A.. Diversidade de peixes no rio mutum e baía marginal no pantanal matogrossense através da coleta ativa. Enciclopédia Biosfera, v.11, n.21, p.2197-2210, 2015.

BRASIL. Constituição da República Federativa do Brasil. Brasília, 1988.

BRITSKI, H. A.; SILIMON, K. Z.; LOPES, B. S.. Peixes do Pantanal: Manual de identificação. Brasília: Embrapa, 2007.

BRITSKI, H. A.; SILIMON, K. Z. S.; LOPES, B. S.. Peixes do Pantanal: manual de identificação. Brasília: Embrapa, 1999.

CORNELL, H. V.; LAWTON, J. H.. Species interactions, local and regional processes, and limits to the richness of ecological communities: a theoretical perspective. Journal of animal ecology, v.61, n.1, p.1-12, 1992. 
ESTEVES, F. A.. Fundamentos de limnologia. Interciência, 1998.

GRAÇA, W. J.; PAVANELLI, C. S.. Peixes da Planície de Inundação do Alto Rio Paraná e Áreas Adjacentes. Maringá: Eduem, 2007.

HELFMAN, G.; COLLETTE, B. B.; FACEY, D. E.; BOWEN, B. W.. The diversity of fishes: biology, evolution, and ecology. John Wiley \& Sons. 2009.

INNOCÊNCIO, N. R.. Hidrografia. Geografia do Brasil, v.4, p.85-112, 1977

JUNK, W. J.. Áreas inundáveis Um desafio para limnologia. Acta Amazônica, v.10, n.4, p.775-795, 1980.

JUNK, W. J.; BAYLEY, P. B.; SPARKS, R. E.. The flood pulse concept in river-floodplain systems. Canadian special publication of fisheries and aquatic sciences, v.106, n.1, p.110-127, 1989.

LEMES, E. M.; GARUTTI, V.. Ecologia da ictiofauna de um córrego de cabeceira da bacia do alto rio Paraná, Brasil. Iheringia: Série Zoologia, v.92, n.3, p.69-78, 2002.

LEMKE, A. P.; SÚAREZ, Y. R.. A composição de espécies de peixes e a diversidade beta podem ser explicadas pelas características físicas e uso do solo em microbacias hidrográficas da bacia do rio Ivinhema?. In: SIMPOSIO DE GEOTECNOLOGIAS NO PANTANAL, 5. Anais. 2014.

LOWE-MCCONNELL, R. H.. Estudos ecológicos de comunidades de peixes tropicais. São Paulo: Edusp, 1999.

MCCONNELL, R.; LOWE-MCCONNELL, R. H.. Ecological studies in tropical fish communities. Cambridge: University Press, 1987.

MOURA, N. A. D.. Morfometria de lagoas marginais da bacia do alto Paraguai: relação com a estrutura e dinâmica das comunidades de peixes no Pantanal de Cáceres/MT. 2010.

MUNIZ, C. C.. Avaliação do papel do pulso de inundação sobre a riqueza e biodiversidade de peixes em ambiente inundável, no sistema de baías caiçara, porção norte do Pantanal Matogrossense, alto Paraguai. Tese (Doutorado) Universidade Federal de São Carlos, 2010.
NELSON, J. S.. Fishes of the World. 4 ed. 2006.

OLIVEIRA, G. Z.. Conhecimento Ecológico tradicional e dieta alimentar de peixes no sistema de baía caiçara no rio Paraguai, Cáceres, Pantanal de Mato Grosso, MT, BRASIL. Tese (Doutorado) - Universidade do Estado de Mato Grosso, 2012.

PAINS-SILVA, H.; PETRY, A. C., SILVA, C. J.. Fish communities of the Pantanal wethand in Brazil: evaluating the effects of the upper Paraguay river flood pulse on baía Caiçara fish fauna. Aquat Ecology, v.44, n.1, p.275-288, 2010.

RESENDE, E. K.; PEREIRA, R. A. C.; ALMEIDA, V. L. L.; SILVA, A. G.. Alimentação de peixes carnivoros da planície inundável do Rio Miranda, Pantanal, Mato Grosso do Sul, Brasil. Embrapa Pantanal-Boletim de Pesquisa e Desenvolvimento, 1996.

RESENDE, E. K.. Pulso de inundação: processo ecológico essencial à vida no Pantanal. Embrapa PantanalDocumentos, 2008.

RODRIGUES, R. R.; GANDOLFI, S.. Conceitos, tendências e ações para a recuperação de florestas ciliares. In: Matas ciliares: conservação e recuperação. São Paulo, 2000.

RODRÍGUEZ, M. A.; LEWIS, W. M.. Structure of fish assemblages along environmental gradients in floodplain lakes of the Orinoco River. Ecological monographs, v.67, n.1, p.109-128, 1997.

SILVA, C. J.; ESTEVES, F. A.. Biomass of three macrophytes in the Pantanal of the Mato Grosso, Brazil. International Journal of Ecology and Environmental Sciences, v.19, p.1123, 1993.

SOUZA, L. P.. Assembleias de peixes em lagos de várzea situados em duas unidades geomorfológicas no período de seca, região de Itacoatiara, Amazonas. Manaus, 2011.

SOUZA, A. R.; MUNIZ, C. C.; OLIVEIRA J. E.. Eichhornia azurea Como HOTSPOT para Macroinvertebrados aquáticos: Ferramenta para a aplicação de índices de avaliação ambiental. Enciclopédia Biosfera, v.15, p.1043-1056, 2018.

SÚAREZ, Y. R.. Variação espacial e temporal na diversidade e composição de espécies de peixes em riachos da bacia do Rio Ivinhema, Alto Rio Paraná. Biota Neotropica, v.8, n.3, 2008.

A CBPC - Companhia Brasileira de Produção Científica (CNPJ: 11.221.422/0001-03) detém os direitos materiais desta publicação. Os direitos referem-se à publicação do trabalho em qualquer parte do mundo, incluindo os direitos às renovações, expansões e disseminações da contribuição, bem como outros direitos subsidiários. Todos os trabalhos publicados eletronicamente poderão posteriormente ser publicados em coletâneas impressas sob coordenação da Sustenere Publishing, da Companhia Brasileira de Produção Científica e seus parceiros autorizados. Os (as) autores (as) preservam os direitos autorais, mas não têm permissão para a publicação da contribuição em outro meio, impresso ou digital, em português ou em tradução. 